\title{
Parametric Study of Stay Cables of a Bridge Under Simulated Spatially Correlated Turbulent Wind
}

\section{Abstract}

The main objective of this work is to carry out a parametric study of stay cables of a bridge under simulated spatially correlated buffeting forces. This vibration mechanism is simulated with an Autoregressive and Moving Average (ARMA) model, and applied to mathematical models of the stay cables of the tallest cablestayed bridge in Mexico. The use of auxiliary damping devices to mitigate vibration is evaluated. The analysis results showed that the use of a more realistic model to represent and characterize the variation in space and time of the fluctuating wind, which is not capture by the white noise or harmonic functions, is advantageous and offers a new alternative to evaluate the structural response of stay cables without and with dampers. The implications of the analyses results in the structural behavior of the stay cables of the bridge are discussed.

Keywords

Cable-stayed bridge; wind-induced response; turbulence; viscous damper; friction damper.
A. Pozos-Estrada ${ }^{\text {a, } 1}$

R. Flores ${ }^{a}, 2$

R. Gómez ${ }^{a, 3}$

${ }^{a}$ Instituto de Ingeniería, Universidad Nacional Autónoma de México, Ciudad de México, México, C.P. 04510, Telephone: (+5255) 56233600 ext. 8482

1 APozosE@iingen.unam.mx

${ }^{2}$ RFloresM@iingen.unam.mx

${ }^{3}$ RGomezM@iingen.unam.mx

http://dx.doi.org/10.1590/1679-78252725

Received 21.12.2015

In revised form 14.03.2016

Accepted 20.03.2016

Available online 23.03.2016

\section{INTRODUCTION}

Stay cables are slender structures with low structural damping, for this reason they are susceptible to vibrations mechanisms such as: buffeting forces, vortex shedding, wind and rain or parametric excitation (Caetano, 2007). These vibrations mechanisms can induce large vibrations of the cables and under specific conditions, instability can be induced as well.

Analytical and experimental investigations about the behavior of stay cables under different vibration mechanisms include the work by Wianecki (1979), who studied the mitigation of the windinduced response of stay cables with the use of dampers, this type of device has proved to be effective since then. Later, Matsumoto et al., $(1989,2001)$ presented results of the wind-induced vibration of stay cables in Japan, they observed that excessive vibrations in stay cables could occur when 
high speed wind flows around them. Other vibration mechanism that can induce large amplitude of the stay cables is the parametric excitation. This type of excitation is discussed in Lilien and Pinto Da Costa (1994). In their study, they developed a finite element model to study parametric excitation induced on the stay cables by the oscillation of the deck or pylon connections. Further, Macdonald et al. (2010) showed that inclined cables can be very susceptible to small motion of the supports and developed a method to identify stability boundaries of the modes of vibration of the cables. Besides analytical investigations, experimental studies have also been carried out to evaluate the response of cables under wind. For example, Cluni et al. (2008) carried out wind tunnel tests to evaluate the wind-induced response of suspended cables and compared the results with a mathematical model. In their study, the turbulent wind forces applied to their mathematical model were obtained from the wind tunnel tests. They pointed out that further analyses were needed to verify the influence of the correlation of the wind forces on the response of the cable.

To evaluate the possible reduction of the excessive vibration of cables, some alternatives can be adopted. In several cases, the use of corrugated cases for the cables is usually enough to reduce the unwanted vibration, and in some other circumstances, the use of auxiliary damping devices is employed to increase the inherent damping of the cables (Ostenfeld-Rosenthal et al., 1992, Gimsing and Georgakis, 2012). The use of auxiliary damping devices to reduce the response on stay cables has become very popular. Hwang et al., (2009) evaluated isolation systems to control the vibration of stay cables and showed that the response can be effectively reduced with the use of stay-cable isolation system. A novel passive approach that consisted in a viscous damper and an elastic spring attached to the end of a cable to reduce vertical vibration was proposed by Jiang et al. (2013), they pointed out that the effectiveness of this damping system depends on the damping coefficient and stiffness of the elastic support. The use of tuned mass dampers (TMDs) to control the vibration of cables was studied by Dong and Jixiang (2014), they found that the use of optimum TMDs to mitigate the vibration of cables produce good results. More recently, Raftoyiannis and Michaltsos (2016) studied the optimum characteristics of dampers to reduce the vibration of cables caused by wind and rain. All the above mentioned studies provided a forward step towards the understanding of the vibration reduction of cables; however, the models adopted to characterize the vibration mechanisms, including wind, are based on harmonic, white noise excitations or free vibration. This prompted us to carry out a parametric study of the stay cables by considering a more realistic characterization of the wind excitation.

The main objective of this work is to carry out a parametric study of the stay cables of the tallest cable-stayed bridge of Mexico under buffeting forces, which are calculated based on simulated time histories of turbulent wind speed. These times histories of turbulent wind speed are simulated with an Autoregressive and Moving Average (ARMA) model and incorporate the spatio-temporal variation of turbulent wind, which is of paramount importance in stay cables. For the analysis, Ansys Parametric Design Language (APDL) was used to study the dynamic structural behavior of stay cables to identify excessive displacements and accelerations within the stay cable or at the connections. The mathematical models of the stay cables were developed with three dimensional elements that incorporate the geometric stiffness and the initial tension. The use of viscous and friction dampers to mitigate the vibration of the stay cables was also analyzed. The implications of 
the analyses results in the structural behavior of the stay cables of the bridge are discussed and the relevance of using a more realistic representation of the turbulent forces is emphasized.

\section{MAIN CHARACTERISTICS OF THE BRIDGE}

The bridge was designed as a cable-stayed bridge with a total length of $1124 \mathrm{~m}$. It is located in a mountain area and spans a canyon of about $390 \mathrm{~m}$ of depth. The bridge has a mid-span of $520 \mathrm{~m}$ and two lateral spans of 250 and $354 \mathrm{~m}$, respectively. The cable system of the bridge consists of two planes of cables with a semifan layout. Each plane of cables contains a total of 38 cables, which makes a total of 76 cables. Cables are anchored to the pylons and to the deck, and are regularly spread along $884 \mathrm{~m}$ of the deck. The length of the cables ranges within 60 to $270 \mathrm{~m}$, approximately. Figure 1 presents a sketch of the bridge.

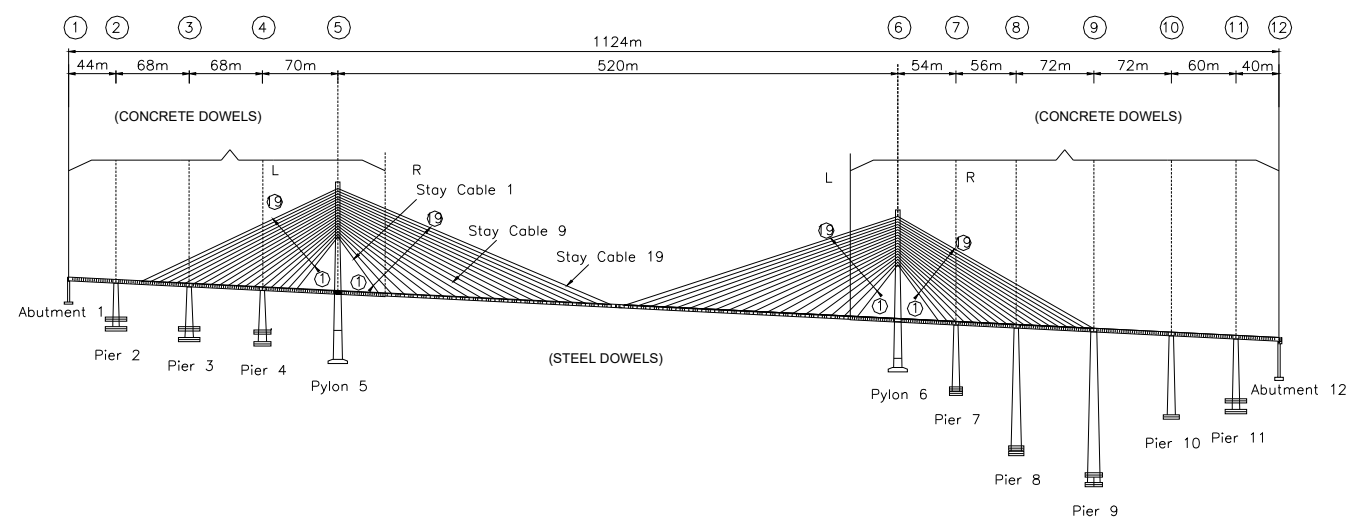

Figure 1: Elevation view of the bridge.

\section{SIMULATION OF BUFFETING FORCES}

\subsection{Determination of Buffeting Forces}

Based on the quasi-steady theory model, where the interaction between the flow and structure can be ignored and the forces are caused by random fluctuating winds, the buffeting force at the time $t$ and at a height $z$ in the along wind direction for a structure can be written as

$$
D(t, z)=\frac{1}{2} \rho C_{D} A(U(z)+u(t))^{2}
$$

where $\rho$ is the air density; $C_{D}$ is the drag coefficient; $A$ is the area exposed to wind; $U(z)$ is the mean wind speed; and $u(t)$ is the fluctuating component of the wind speed. It is noted that $U(z)$ depends on the height and the roughness of the terrain. In this study a power law function proposed by Davenport (1965) for very rough terrain is used to describe the variation of $U(z)$ with height given by 


$$
U(z)=U\left(z_{r e f}\right)\left(\frac{z}{z_{r e f}}\right)^{0.4}
$$

where $U\left(z_{r e f}\right)$ is a reference mean wind speed at a reference height.

The turbulent wind speed $u(t)$ is often considered a Gaussian stochastic process and is usually characterized by its power spectral density function (PSDF). An approach to simulate $u(t)$ as a Gaussian stochastic process is the use of the ARMA model. The ARMA model considers the combination of a Gaussian white noise vector, $\left\{\varepsilon_{i}\right\}$, with the moving average and autoregressive coefficients denoted respectively by $\left\{\alpha_{\mathrm{i}}\right\}$ and $\left\{\beta_{\mathrm{i}}\right\}$, with the purpose of simulating a sample of a stochastic stationary process (Samaras, 1985). Based on the ARMA coefficients and the white noise vector, the following expression can be used to simulate samples of turbulent wind velocities

$$
\left\{u_{n}(x, z, t)\right\}=\sum_{i=1}^{p}\left[\alpha_{i}\right]\left\{u_{n}(x, z, t-i \Delta t)\right\}+\sum_{i=1}^{q}\left[\beta_{i}\right]\left\{\varepsilon_{i}\right\}
$$

where $\left\{u_{n}(x, z, t)\right\}$ is a vector of turbulent wind velocities for any time $t$ at point $(x, z)$ with zero mean and unit variance. The orders of the moving average and auto regression are denoted by $p$ and $q$, respectively. Figure 2 illustrates the plane of exposure of a stay cable subjected to a turbulent wind field.

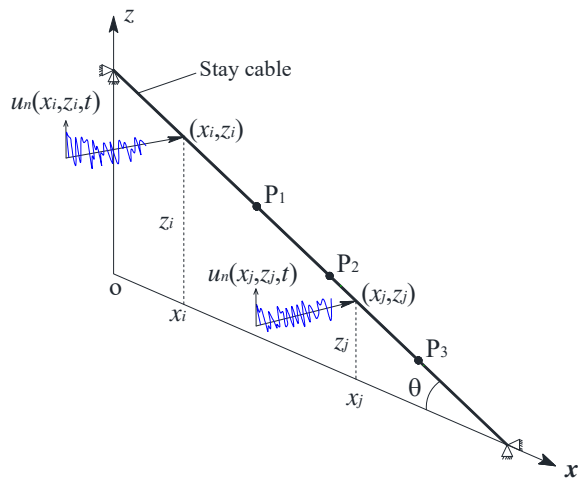

Figure 2: Plane of exposure of a stay cable subjected to the turbulent wind field.

To estimate the coefficients $\left\{\alpha_{\mathrm{i}}\right\}$ and $\left\{\beta_{\mathrm{i}}\right\}$, it is necessary to define the PSDF as well as the coherence function of the turbulent wind. Numerous expressions have been proposed in the literature to characterize the PSDF of the turbulent wind. In the following, the one sided spectrum given by Kaimal and Finnigan (1994) is adopted and written as

$$
\frac{f S(f, z)}{\sigma_{u}^{2}}=\frac{22 z / U(z)}{(1+33 f z / U(z))^{\frac{5}{3}}}
$$


where $\sigma_{u}^{2}$ is the variance of the turbulent wind, $f$ denotes frequency, in Hertz, and $U(z)$ is the variation of the mean wind speed given in Eq. (2).

The functional form of the coherence function of the turbulent wind adopted is the one proposed by Davenport (1968). If the plane of exposure shown in Figure 2 is considered, the coherence function can be written as

$$
\operatorname{coh}\left(x_{i}, z_{i}, x_{j}, z_{j}, f\right)=\exp \left[-\frac{f\left[C^{2}{ }_{x}\left(x_{i}-x_{j}\right)^{2}+C^{2}{ }_{z}\left(z_{i}-z_{j}\right)^{2}\right]}{\left[U\left(z_{i}\right)+U\left(z_{j}\right) / 2\right]}\right]
$$

where $C_{x}$ and $C_{z}$ are coefficients that take into account the exponential decay. With the expressions defined above, samples of $\left\{u_{n}(x, z, t)\right\}$ are simulated and employed to estimate samples of turbulent wind forces by using Eq. (1). The parameters employed in the simulation are summarized in Table 1.

\begin{tabular}{ccc}
\hline \hline Parameter & Symbol & Value \\
\hline Observation time (s) & $T$ & 600 \\
Time increment (s) & $\Delta t$ & 0.1 \\
Nyquist frequency (Hz) & $f_{N}$ & 5 \\
Lower and upper bounds of frequency $(\mathrm{Hz})$ & $f_{L}, f_{U}$ & $0.001,5$ \\
Frequency increment (Hz) & $\Delta f$ & 0.001 \\
Order of ARMA model & $p, q$ & 5,5 \\
Decay coherence coefficients & $C_{x}, C_{z}$ & 16,10 \\
\hline \hline
\end{tabular}

Table 1: Parameters employed in the simulation of wind records.

Figure 3a presents a sample of the simulated turbulent wind speed for a predefined height. To verify the frequency content of the simulated turbulent wind speed records, Figure $3 \mathrm{~b}$ presents a comparison of the theoretical and estimated PSDF based on Welch (1967) of a simulated record. It is observed from this figure that the PSDFs have good agreement. In Figure 3c, a comparison of three empirical cross correlation functions of simulated turbulent wind speeds at predefined points along the stay cable are shown. As expected, the correlation among wind speed records at two points decreases as the distance between them increases. Similar results were obtained for the wind speed records simulated for the stay cables analyzed.
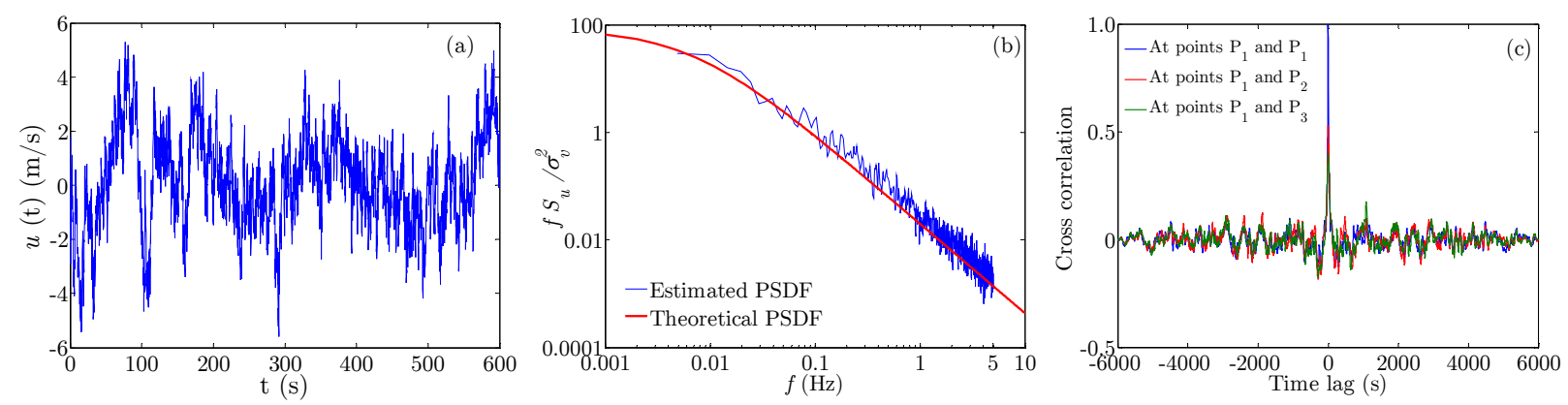

Figure 3: Simulated turbulent wind: (a) typical sample; (b) comparison of theoretical and estimated PSDF of the simulated record; (c) cross correlation between turbulent wind speeds between points $\mathrm{P}_{1}, \mathrm{P}_{2}$ and $\mathrm{P}_{3}$ (these points are shown in Figure 2). 


\section{MATHEMATICAL MODELING OF THE STAY CABLES}

ANSYS Parametric Design Language (2013) was used to model selected stay cables of the bridge. Element BEAM4, a three dimensional element that can incorporate the geometric stiffness and the initial tension of the stay cable was used. Note that the modeling of the initial tension of the cable is important since the natural frequency of the stay cables depends on it.

A convergence analysis of the first natural frequency of the stay cables modeled was carried out in order to define the total number of elements into which the mathematical model of the stay cables needed to be discretized. Stay cables were discretized in 100 elements (with a total number of nodes of 101) in order to improve the accuracy of the analytical results. Simulated turbulent wind forces were applied only to odd nodes. The boundary conditions of the stay cables were considered pinned at the supports. The structural damping ratio, $\xi$, of the stay cables considered ranged from $0.1 \%$ to $0.5 \%$ (Kumarasena, 2007; Macdonald et al., 2010). It is worth mentioning that the aerodynamic damping effect is not considered in this study, although if wanted, theoretical expressions to calculate the aerodynamic damping based on a wind direction-dependent factor could be employed (Macdonald et al., 2010). The properties of the stay cables selected for the modeling and analysis are presented in Table 2.

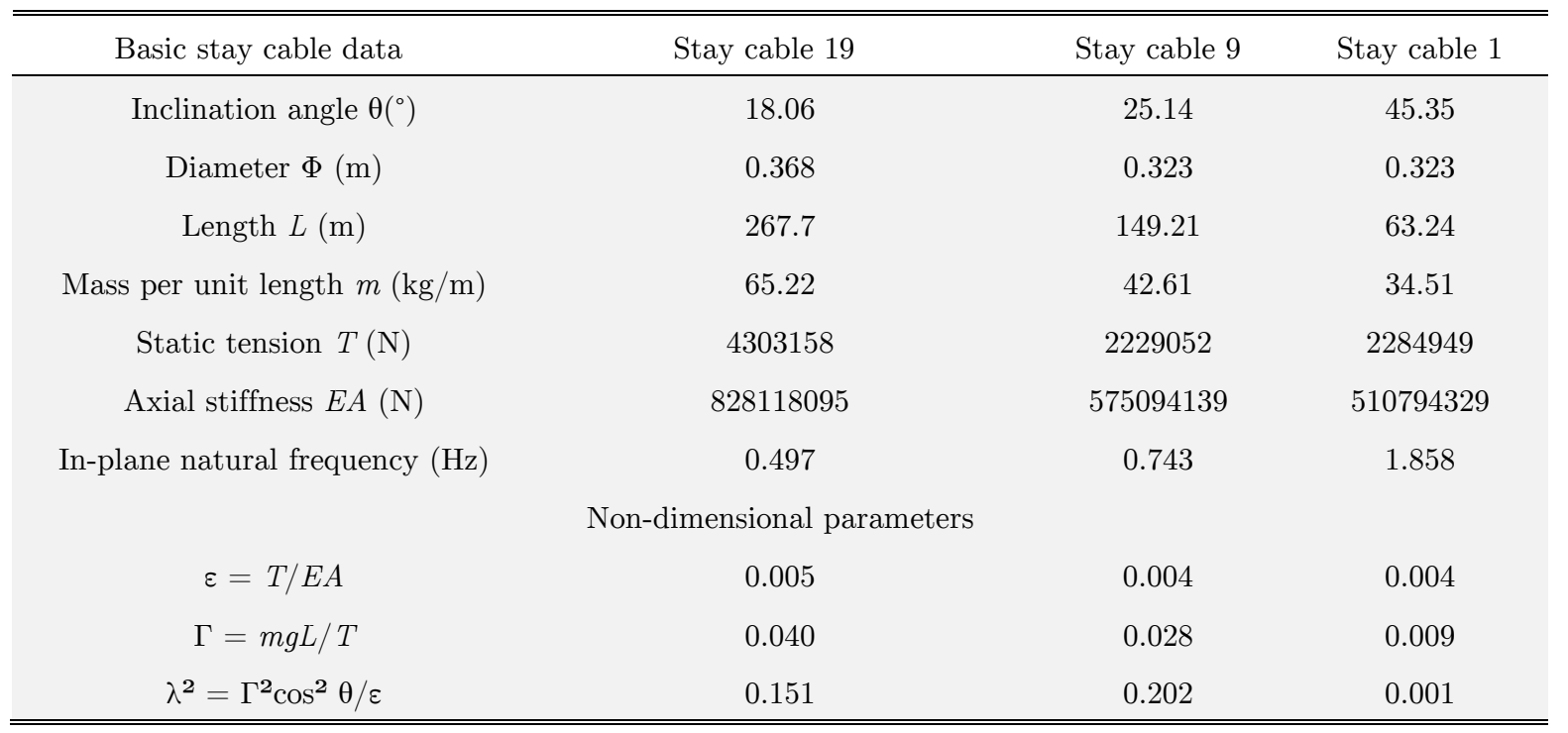

Table 2: Properties of the stay cables analyzed.

Stay cables are usually fitted with auxiliary damping devices such as viscous or friction dampers to increase their low inherent damping. In order to study the effectiveness of the dampers in the stay cables modeled, a viscous and a friction damper are employed to mitigate the response of the cable subjected to turbulent wind. The ANSYS elements COMBIN14 and COMBIN40 are used to model the viscous and friction damper, respectively. Figure 4 depicts the stay cables without and with dampers. 


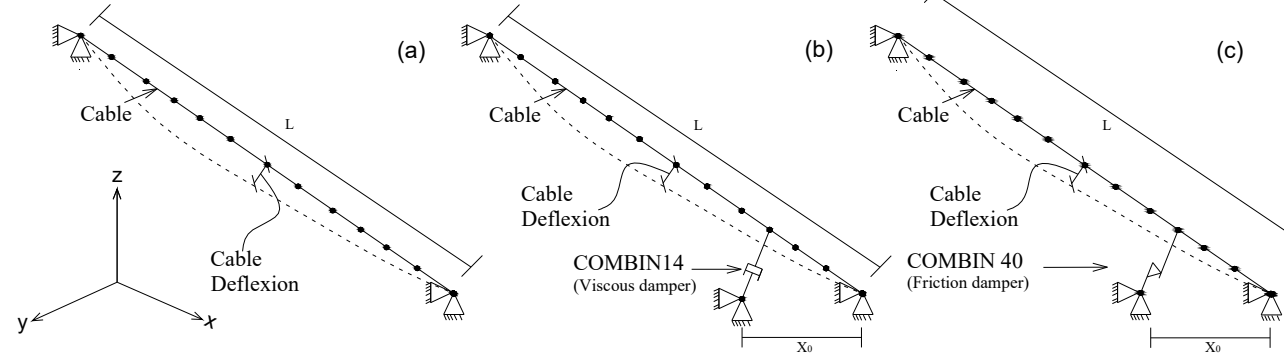

Figure 4: Mathematical models of the stay cables: (a) without dampers;

(b) fitted with viscous damper; (c) fitted with friction damper.

\section{NUMERICAL ANALYSIS AND RESULTS}

\subsection{Stay Cables Without and With Viscous Dampers Subjected to Buffeting Forces}

For the parametric analysis, stay cables subjected to buffeting forces associated with different reference mean wind speeds were considered. The analysis was performed using time histories of $600 \mathrm{~s}$ duration with a time step of $0.1 \mathrm{~s}$.

As explained in Section 4, stay cables are modeled varying the damping ratio. For the moment, consider that stay cable number 1 (see Table 2) is subjected to buffeting forces for a mean wind speed at $z_{\text {ref, where }} \mathrm{z}_{\text {ref }}$ is deck height, equal to $20 \mathrm{~m} / \mathrm{s}$. For these buffeting forces, the variation of the displacement of the stay cable at a horizontal distance $x_{0}=0.05 \mathrm{~L}$ from the cable-deck connection by considering damping ratios equal to $0.15,0.3$ and $0.5 \%$ is shown in Figure 5 .

It is observed in Figure 5 that the increase in damping ratio reduces the response of the stay cable as expected. The same analyses were repeated for stay cables 9 and 19. Similar conclusions to those drawn for stay cable 1 are applicable to stay cables 9 and 19, except that the effect of increasing the damping ratio on the response of these stay cables seems to be more significant to that of stay cable 1, as shown in Figures 5b and 5c. It is also observed from these plots that the variation of the time histories of the response differs from those when wind speed is modeled as white noise or a harmonic function.
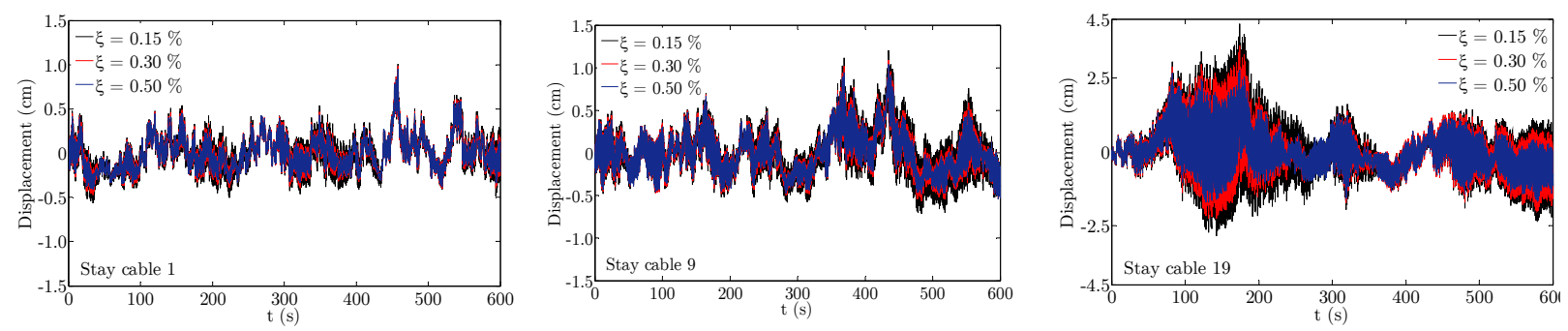

Figure 5: Time history of displacements of stay cables for $U(r e f)$ equal to $20 \mathrm{~m} / \mathrm{s}$ and different damping ratios at $x_{0}=0.05 \mathrm{~L}$. 
To better appreciate the effect of structural damping on the stay cables considered, Tables 3 and 4 summarize the variation of the peak and root-mean-square (rms) displacement and acceleration for different mean wind speeds. The results outside brackets refer to the peak response, while those inside brackets correspond to the rms response.

\begin{tabular}{c|ccc|ccc|ccc}
\hline \hline $\begin{array}{c}\text { U(ref) } \\
(\mathrm{m} / \mathrm{s})\end{array}$ & $\xi=0.15 \%$ & $\xi=0.30 \%$ & $\xi=0.50 \%$ & $\xi=0.15 \%$ & $\xi=0.30 \%$ & $\xi=0.50 \%$ & $\xi=0.15 \%$ & $\xi=0.30 \%$ & $\xi=0.50 \%$ \\
\hline \multirow{3}{*}{5} & 0.04 & 0.04 & 0.03 & 0.05 & 0.04 & 0.04 & 0.10 & 0.10 & 0.10 \\
& $(0.01)$ & $(0.01)$ & $(0.01)$ & $(0.01)$ & $(0.01)$ & $(0.01)$ & $(0.03)$ & $(0.30)$ & $(0.03)$ \\
& 0.21 & 0.20 & 0.19 & 0.22 & 0.20 & 0.19 & 0.68 & 0.62 & 0.57 \\
10 & $(0.05)$ & $(0.05)$ & $(0.04)$ & $(0.06)$ & $(0.05)$ & $(0.05)$ & $(0.17)$ & $(0.15)$ & $(0.14)$ \\
& 0.46 & 0.42 & 0.40 & 0.57 & 0.56 & 0.54 & 1.33 & 1.22 & 1.04 \\
15 & $(0.12)$ & $(0.11)$ & $(0.10)$ & $(0.16)$ & $(0.15)$ & $(0.14)$ & $(0.39)$ & $(0.36)$ & $(0.32)$ \\
& 1.01 & 0.99 & 0.95 & 1.21 & 1.09 & 1.04 & 4.34 & 3.60 & 2.77 \\
20 & $(0.21)$ & $(0.19)$ & $(0.18)$ & $(0.28)$ & $(0.25)$ & $(0.24)$ & $(1.02)$ & $(0.85)$ & $(0.71)$ \\
& 1.84 & 1.31 & 1.29 & 1.67 & 1.58 & 1.48 & 4.65 & 4.53 & 4.48 \\
25 & $(0.44)$ & $(0.34)$ & $(0.30)$ & $(0.43)$ & $(0.41)$ & $(0.39)$ & $(1.21)$ & $(1.07)$ & $(0.97)$ \\
& 2.37 & 2.27 & 2.28 & 3.06 & 2.74 & 2.55 & 7.45 & 6.67 & 5.71 \\
30 & $(0.60)$ & $(0.51)$ & $(0.46)$ & $(0.85)$ & $(0.71)$ & $(0.64)$ & $(1.81)$ & $(1.59)$ & $(1.39)$ \\
\hline \hline
\end{tabular}

Table 3: Peak and rms of displacement $(\mathrm{cm})$ for the stay cables studied.

\begin{tabular}{c|ccc|ccc|ccc}
\hline \hline $\begin{array}{c}\text { U(ref) } \\
(\mathrm{m} / \mathrm{s})\end{array}$ & \multicolumn{3}{|c|}{ Stay cable 1 } & \multicolumn{3}{c|}{ Stay cable 9} & \multicolumn{3}{c}{ Stay cable 19 } \\
\hline \multirow{3}{*}{5} & $0.15 \%$ & $\xi=0.30 \%$ & $\xi=0.50 \%$ & $\xi=0.15 \%$ & $\xi=0.30 \%$ & $\xi=0.50 \%$ & $\xi=0.15 \%$ & $\xi=0.30 \%$ & $\xi=0.50 \%$ \\
& $(0.05)$ & $(0.03)$ & $(0.03)$ & $(0.01)$ & $(0.01)$ & $(0.01)$ & $(0.03)$ & $(0.02)$ & $(0.01)$ \\
& 0.88 & 0.71 & 0.58 & 0.37 & 0.25 & 0.23 & 0.33 & 0.26 & 0.23 \\
10 & $(0.19)$ & $(0.15)$ & $(0.12)$ & $(0.09)$ & $(0.06)$ & $(0.05)$ & $(0.09)$ & $(0.07)$ & $(0.05)$ \\
& 2.68 & 2.20 & 1.71 & 0.83 & 0.70 & 0.57 & 1.07 & 0.78 & 0.58 \\
15 & $(0.66)$ & $(0.49)$ & $(0.39)$ & $(0.17)$ & $(0.13)$ & $(0.10)$ & $(0.26)$ & $(0.19)$ & $(0.14)$ \\
& 6.79 & 5.67 & 4.61 & 1.82 & 1.38 & 1.05 & 2.62 & 2.10 & 1.63 \\
20 & $(1.16)$ & $(0.88)$ & $(0.69)$ & $(0.38)$ & $(0.28)$ & $(0.21)$ & $(0.55)$ & $(0.40)$ & $(0.30)$ \\
& 10.77 & 9.13 & 6.77 & 2.68 & 2.06 & 1.57 & 4.93 & 3.56 & 2.40 \\
25 & $(2.38)$ & $(1.72)$ & $(1.34)$ & $(0.64)$ & $(0.48)$ & $(0.38)$ & $(0.79)$ & $(0.58)$ & $(0.43)$ \\
& 13.78 & 10.81 & 8.76 & 5.85 & 5.10 & 4.19 & 4.35 & 3.33 & 2.99 \\
30 & $(4.12)$ & $(3.18)$ & $(2.54)$ & $(0.98)$ & $(0.72)$ & $(0.56)$ & $(1.23)$ & $(0.91)$ & $(0.68)$ \\
\hline \hline
\end{tabular}

Table 4: Peak and $\mathrm{rms}$ of acceleration $\left(\mathrm{m} / \mathrm{s}^{2}\right)$ for the stay cables studied.

The results from Table 3 and 4 show a typical behavior of the response under buffeting forces. It is also observed from these tables that an increase in the structural damping ratio seems to be more effective for reducing the peak or rms response in stay cables 9 and 19 (long stay cables).

To evaluate the effectiveness of the viscous damper, the analyses described above were repeated but this time a viscous damper was fitted to each stay cable (see Figure 4b). An important consideration during the selection of the size of this damper is its location on the deck with respect to the cable-deck connection (i.e., $x_{0}$ shown in Figure 4b). For practical reasons this location is usually limited to a few meters near the cable-deck connection (Pacheco et al., 1993). For all the analyses, 
the damping ratio of the analyzed stay cables was set equal to $0.15 \%$ and $x 0=0.05 L$. A parametric analysis was carried out by varying the coefficient of damping of the viscous dampers, $C$. To evaluate the effectiveness of the viscous dampers to reduce the peak and rms response, response ratios can be employed (Pozos-Estrada and Hong, 2015). These ratios of the peak and rms response (displacement and acceleration) of the stay cable with and without viscous damper at the location of the damper are measured and calculated as

$$
\begin{gathered}
R_{D i}=D_{w d} / D_{w o} \\
R_{A i}=A_{w d} / A_{w o}
\end{gathered}
$$

where the subscript $i=p$ (peak), $r$ (rms); $D_{w d}$ and $A_{w d}$ denote the (maximum) peak or rms displacement and acceleration of the structure with a viscous damper, respectively, while $D_{w o}$ and $A_{w o}$ denote the (maximum) peak or rms displacement and acceleration of the structure without a viscous damper, respectively. Figure 6 and 7 depicts the results of the analyses.
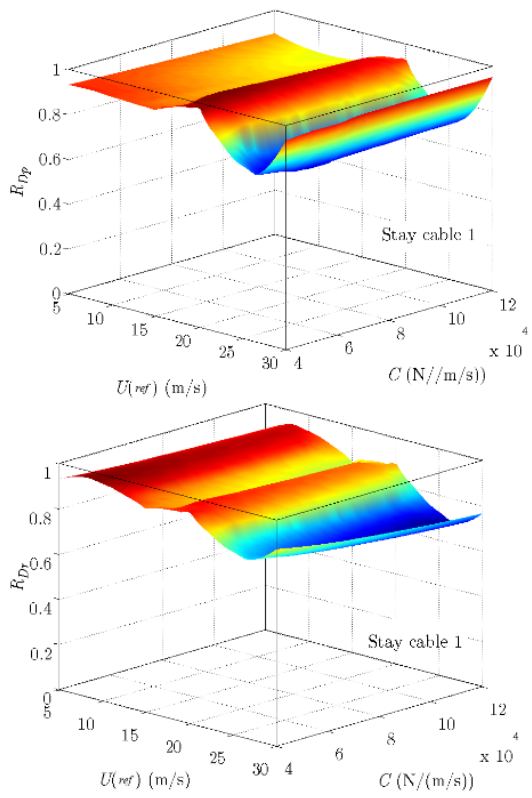

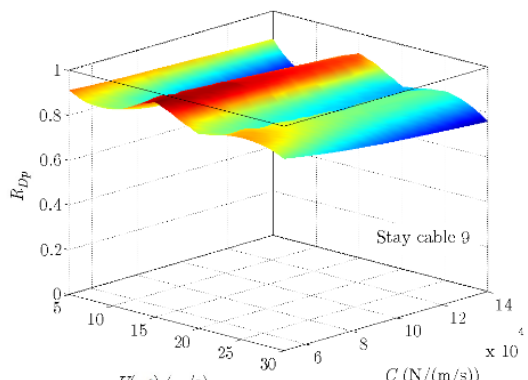

$C(\mathrm{~N} /(\mathrm{m} / \mathrm{s}))$

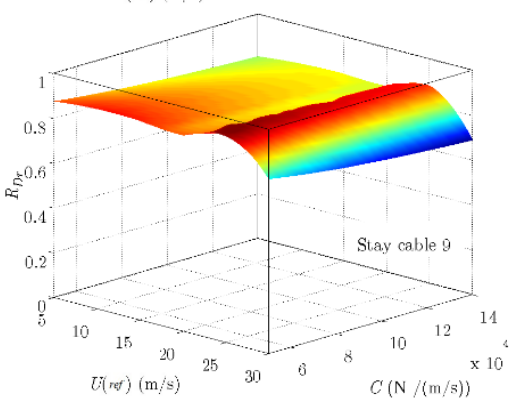

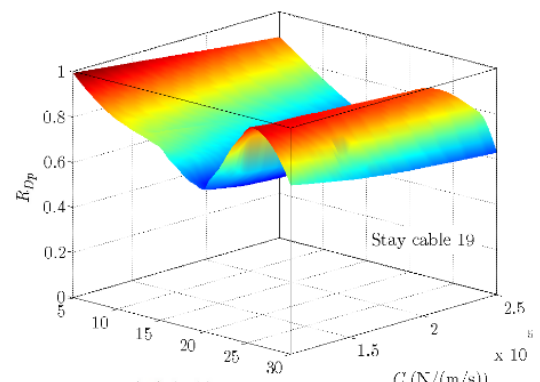

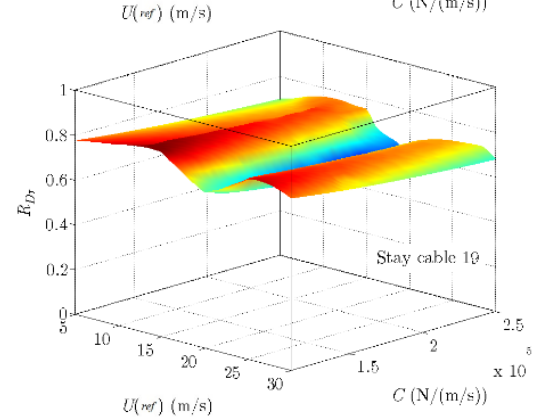

Figure 6: Variation of $R_{D p}$ and $R_{D r}$ with $U(r e f)$ and $C$.

It is observed from figure 6 that $\mathrm{R}_{\mathrm{Di}}$ is very sensitive to $\mathrm{U}(\mathrm{ref})$. It is also observed that no significant reduction is achieved by increasing the coefficient of viscous damper. It is important to point out that an excessive increase in the coefficient of damping of the viscous damper could produce the effect of a virtual support at the location of the damper, which could cause a reduction of the effectiveness of the damper to dissipate energy. It is also observed in figure 6 that, in general, the viscous damper is more effective for values of $U($ ref $)$ greater than $10 \mathrm{~m} / \mathrm{s}$, and that the amount of reduction of the response depends on the type of response to be reduced (peak or rms). A comparison of the results shown in Figures 6 shows that the maximum reduction achieved with the use of viscous dampers was about $30 \%, 25 \%$ and $40 \%$ for stay cables 1, 9 and 19, respectively, when the peak 
response is considered, and 30\%, 30\% and 40\% when the rms response is considered. Similar conclusions to those drawn for Figure 6 are applicable to Figure 7, except that the use of viscous dampers to reduce the peak and rms acceleration is effective for the range of wind speeds considered.

The identified parameters associated with the minimum response ratios at the midpoint of stay cables 1, 9 and 19 are summarized in Table 5. It is observed from this table that the same type of viscous damper could be employed to mitigate the peak or rms displacement and acceleration. It is also observed from the table that the maximum reduction achieved were $56 \%, 57 \%$ and $58 \%$ for stay cable 1, 9 and 19, respectively.
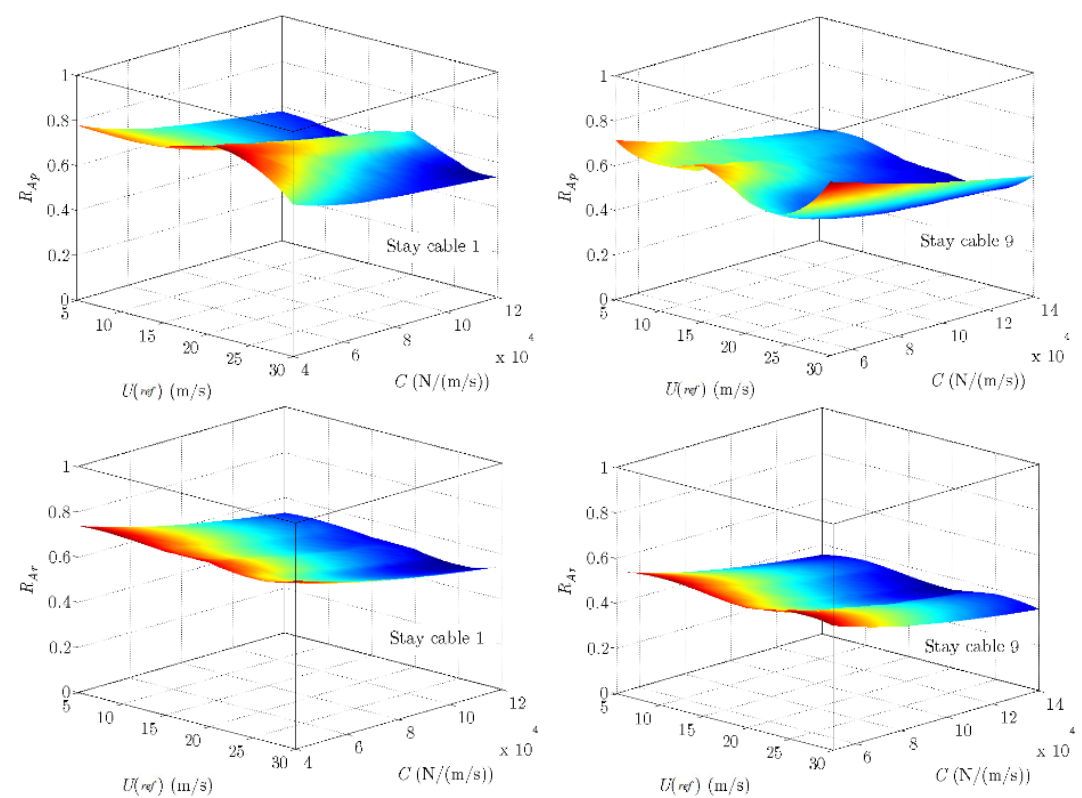
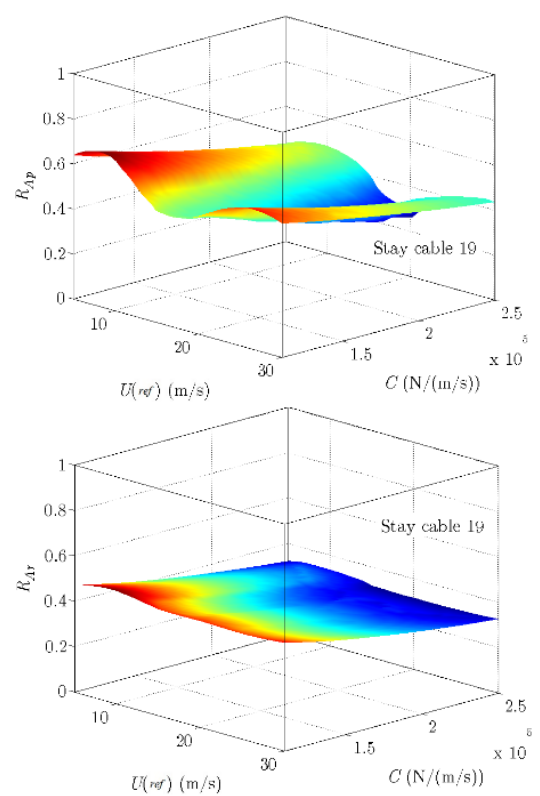

Figure 7: Variation of $R_{A p}$ and $R_{A r}$ with $U(r e f)$ and $C$.

\begin{tabular}{|c|c|c|c|c|c|c|}
\hline \multirow{2}{*}{ Ratio } & \multicolumn{2}{|c|}{ Stay cable 1} & \multicolumn{2}{|c|}{ S Stay cable 9} & \multicolumn{2}{|c|}{ Stay cable 19} \\
\hline & $U(r e f)(\mathrm{m} / \mathrm{s})$ & $C(\mathrm{~N} /(\mathrm{m} / \mathrm{s}))$ & $U(r e f)(\mathrm{m} / \mathrm{s})$ & $C(\mathrm{~N} /(\mathrm{m} / \mathrm{s}))$ & $U(r e f)(\mathrm{m} / \mathrm{s})$ & $C(\mathrm{~N} /(\mathrm{m} / \mathrm{s}))$ \\
\hline$R_{D p}$ & \multicolumn{2}{|c|}{0.663} & \multicolumn{2}{|c|}{0.784} & \multicolumn{2}{|c|}{0.539} \\
\hline & 25 & 80,000 & 30 & 140,000 & 20 & 250,000 \\
\hline$R_{D r}$ & \multicolumn{2}{|c|}{0.668} & \multicolumn{2}{|c|}{0.672} & \multicolumn{2}{|c|}{0.566} \\
\hline & 25 & 120,000 & 30 & 140,000 & 20 & 250,000 \\
\hline$R_{A p}$ & \multicolumn{2}{|c|}{0479} & \multicolumn{2}{|c|}{0.496} & \multicolumn{2}{|c|}{0.431} \\
\hline \multirow[t]{2}{*}{$R_{A r}$} & \multicolumn{2}{|c|}{0.439} & \multicolumn{2}{|c|}{0.425} & 15 & 250,000 \\
\hline & 25 & 120,000 & 30 & 140,000 & 20 & 250,000 \\
\hline
\end{tabular}

Table 5: Identified parameters associated with the minimum response ratios at the midpoint of the stay cables fitted with viscous dampers.

\subsection{Stay Cables With Friction Dampers Subjected to Buffeting Forces}


Friction dampers with dry-friction behavior were considered. For this type of damper, damping forces are developed when relative motion between the interfaces of adjacent members occurs (see Figure 4c). For all the analyses a damping ratio equal to $0.15 \%$ was considered for stay cables 1,9 and 19. Figures 8 and 9 show the analysis results.
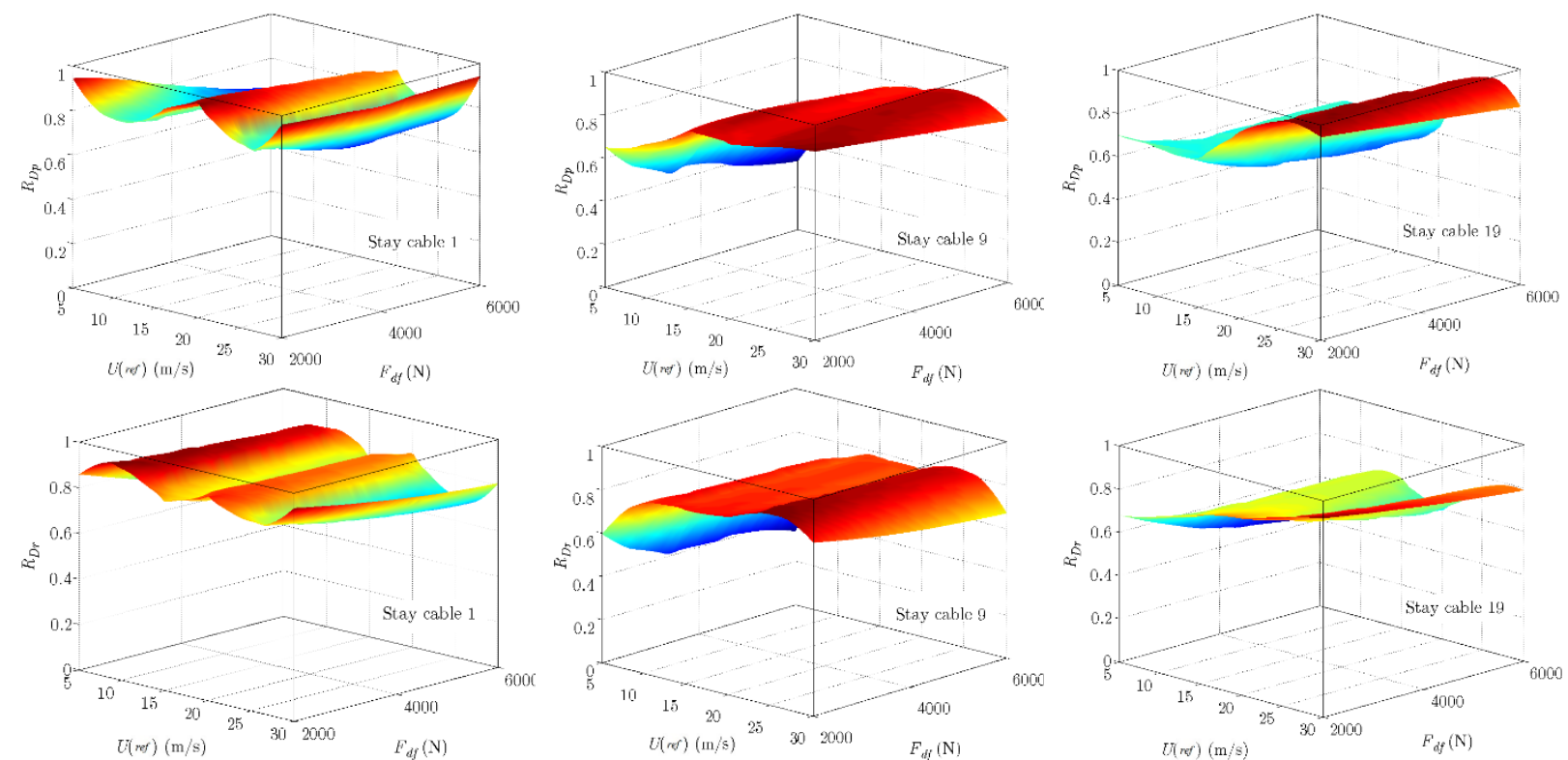

Figure 8: Variation of $R_{D p}$ and $R_{D r}$ with $U(r e f)$ and $F_{d f}$.
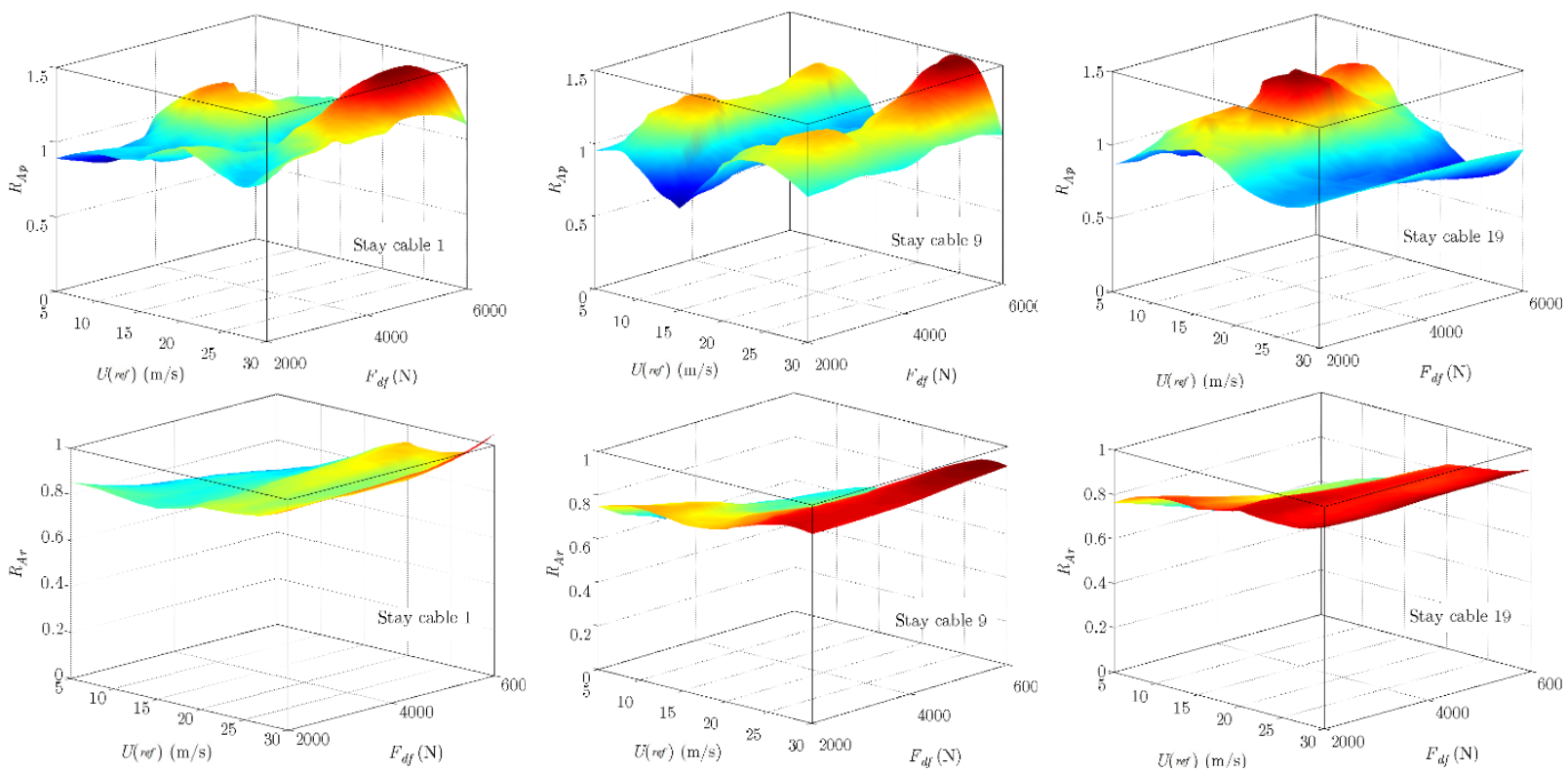

Figure 9: Variation of $R_{A p}$ and $R_{A r}$ with $U(r e f)$ and $F_{d f}$.

It is observed from figure 8 that $R_{D i}$ is more sensitive to $U(r e f)$ than $F_{d f}$, and that, in general, the use of this type of damper is more effective for values of $U($ ref $)$ within 5 to $15 \mathrm{~m} / \mathrm{s}$. The maxi- 
mum reduction achieved with the use of friction dampers was about $34 \%, 68 \%$ and $55 \%$ for stay cables 1, 9 and 19, respectively, when the peak response is considered, and $40 \%, 66 \%$ and $59 \%$ when the rms response is considered. When the friction damper is employed to mitigate the peak acceleration, it is observed in figure 9 that $R_{A p}$ is greater than 1 for most of the $U($ ref $)$ values considered, indicating that the use of friction dampers are not effective for this case. Moreover, it is observed in figure 9 that $R_{A r}$ is reduced with the employed of friction dampers, this reduction is more effective for values of $U($ ref $)$ within 5 to $15 \mathrm{~m} / \mathrm{s}$. Similar to the results shown in figures 6 and 7 , the results presented is figures 8 and 9 indicate that the reduction depends on the type of response considered.

To observe the amount of reduction of the response with the use of friction damper at the midpoint of the stay cables 1, 9 and 19, Table 6 summarizes the results. It is observed in this table that the $U(r e f)$ values associated with the minimum response vary from 15 to $30 \mathrm{~m} / \mathrm{s}$, and that for the longer stay cables (9 and 19) the use of the same type of damper could be employed to mitigate the peak or rms displacement and acceleration. It is interesting to note that, $R_{A p}$ is also reduced, indicating that friction dampers are effective to reduce the response at the midpoint of the stay cables considered.

\begin{tabular}{|c|c|c|c|c|c|c|}
\hline \multirow{2}{*}{ Ratio } & \multicolumn{2}{|c|}{ Stay cable 1} & \multicolumn{2}{|c|}{ Stay cable 9} & \multicolumn{2}{|c|}{ Stay cable 19} \\
\hline & $U(r e f)(\mathrm{m} / \mathrm{s})$ & $F d f(\mathrm{~N})$ & $U(r e f)(\mathrm{m} / \mathrm{s})$ & $F d f(\mathrm{~N})$ & $U(r e f)(\mathrm{m} / \mathrm{s})$ & $F d f(\mathrm{~N})$ \\
\hline$R_{D p}$ & \multicolumn{2}{|c|}{0.679} & \multicolumn{2}{|c|}{0.771} & \multicolumn{2}{|c|}{0.594} \\
\hline & 25 & 4,000 & 30 & 6,000 & 20 & 6,000 \\
\hline$R_{D r}$ & \multicolumn{2}{|c|}{0.653} & \multicolumn{2}{|c|}{0.657} & \multicolumn{2}{|c|}{0.587} \\
\hline & 25 & 6,000 & 30 & 6,000 & 20 & 6,000 \\
\hline$R_{A p}$ & \multicolumn{2}{|c|}{0.497} & \multicolumn{2}{|c|}{0.444} & \multicolumn{2}{|c|}{0.422} \\
\hline \multirow{3}{*}{$R_{A r}$} & 15 & 4,000 & 15 & 3,000 & 15 & 6,000 \\
\hline & \multicolumn{2}{|c|}{0.421} & \multicolumn{2}{|c|}{0.423} & \multicolumn{2}{|c|}{0.369} \\
\hline & 15 & 6,000 & 30 & 6,000 & 15 & 6,000 \\
\hline
\end{tabular}

Table 6: Identified parameters associated with the minimum response ratios at the midpoint of the stay cables fitted with friction dampers.

\section{CONCLUSIONS}

A parametric analysis of isolated cables of the Baluarte bridge under spatially correlated buffeting forces was carried out. Stay cables without and with dampers were modeled in the commercial program ANSYS by means of APDL code. The results of the analyses show that in general the use of viscous or friction dampers can help to reduce the response of the stay cables at the location of the damper or at the midpoint, however, no reduction of the peak acceleration was achieved.

Other conclusions that can be drawn from this study are:

- The employ of an ARMA model is useful to simulate and characterize turbulent wind. Its implementation is not a demanding task, and it allows to evaluate more realistic results compared to the use of white noise or harmonic functions to represent turbulent wind.

- It was observed that when viscous dampers were fitted to stay cables, the response ratio $R_{D i}$ was very sensitive to the values of $U(r e f)$ and that no significant reduction is achieved by increasing the coefficient of viscous damper. 
- The viscous dampers are more effective to reduce the response, at the location of the damper, when the stay cables are subjected to $U($ ref $)$ greater than $10 \mathrm{~m} / \mathrm{s}$.

- When friction dampers were fitted to stay cables, the response ratio $R_{D i}$ was more sensitive to $U($ ref $)$ than $F_{d f}$.

- In general, the use of friction dampers, at the location of the damper, is more effective to reduce displacements when the stay cables are subjected to $U($ ref $)$ within 5 to $15 \mathrm{~m} / \mathrm{s}$.

- The use of friction dampers to mitigate $R_{A p}$ at the location of the damper is not effective for the cases considered.

- In all cases considered, the use of viscous and friction dampers mitigated the response of the stay cables at their midpoint.

- The amount of reduction of the response when viscous or friction dampers are employed depends on the type of response to be reduced (displacement, acceleration, peak or rms).

The analysis results showed that the use of a more realistic model to represent and characterize the variation in space and time of the fluctuating wind, which is not captured by the white noise or harmonic functions, is advantageous and offers a new alternative to evaluate the structural response of stay cables without and with dampers.

\section{Acknowledgements}

The financial support provided by DGAPA through project PAPIIT IA100614 is greatly acknowledged. The first author would also like to thank the financial support provided by the National Council for Science and Technology (CONACYT) of Mexico.

\section{References}

ANSYS Inc. (2013), ANSYS release 13, academic version.

Caetano, E. (2007). Cable vibrations in Cable-Stayed Bridges, International Association for Bridge and Structural Engineering, Structural Engineering Documents, No. 9, pp.188.

Cluni, F., Gusella, V., Bartoli, G. (2008). Wind tunnel scale model testing of suspended cables and numerical comparison. Journal of Wind Engineering and Industrial Aerodynamics, 96(6-7): 1134-1140.

Davenport A.G. (1968). The dependence of wind load upon meteorological parameters. In proceedings of the International Research Seminar on Wind Effects on Buildings and Structures. University of Toronto Press, Toronto, pp. 1982.

Davenport, A.G. (1965). The relationship of wind structure to wind loading. In proceeding of the symposium on Wind Effects on Buildings and Structures. Vol.1. National Physical Laboratory. Teddington, U.K., Her Majesty's Stationary Office, London, pp. 53-102.

Dong L., Jixiang S. (2014). Theoretical study on cable's vibration control by single TMD. Advanced Materials Research, 935: 211-214.

Gimsing N.J., Georgakis C.T. (2012). Cable supported bridges: Concept and Design. Wiley, pp. 590.

Hwang I., Lee J.S., Spencer B.F. (2009). Isolation System for Vibration Control of Stay Cables. Journal of Engineering Mechanics, 135(1): 62-66.

Jiang J., Li G.Q., Lu Y. (2013). Vibration control of cables with damped flexible end restraint: Theoretical model and experimental verification. Journal of Sound and Vibration, 332: 3626-3645. 
Kaimal J.K., and Finnigan, J.J. (1994). Atmospheric boundary layer flows. New York: Oxford University Press. pp.289.

Lilien, J.L., and Pinto Da Costa, A. (1994). Vibration amplitude caused by parametric excitation of cable stayed structures. Journal of Sound and Vibration, 174(1): 69-90.

Macdonald J.H.G, Dietz M.S, Neild S.A et al. (2010). Generalised modal stability of inclined cables subjected to support excitations. Journal of Sound and Vibration, 329: 4515-4533.

Matsumoto, M, Yokoyama, K, Miyata, T, Fujino, Y, Saitoh, T. (1989). Wind-induced cable vibration of cable-stayed bridges in japan, Canada-Japan. Workshop on Bridge Aerodinamics, Ottawa, Canada, 1989, pp. 101-110.

Matsumoto, M., Yagia, T., Shigemurab, Y., Tsushimac, D. (2001). Vortex-induced cable vibration of cable-stayed bridges at high reduced wind velocity. Journal of Wind Engineering and Industrial Aerodynamics, 89: 633-647.

Ostenfeld-Rosenthal, P., Madsen. H.A., Larsen, A. (1992). Probabilistic flutter criteria for long span bridges. Journal of Wind Engineering and Industrial Aerodynamics, 42(1-3): 1265-1276.

Pacheco, B., Fujino, Y., Sulekh, A. (1993). Estimation Curve for Modal Damping in Stay Cables with Viscous Damper. Journal of Structural Engineering, 119(6): 1961 - 1979.

Pozos-Estrada, A. and H. P. Hong, (2015). Sensitivity Analysis of the Effectiveness of Tuned Mass Dampers to Reduce the Wind-Induced Torsional Response, Latin American Journal of Solids and Structures, 12(13): 2520-2538.

Raftoyiannis I.G., Michaltsos G.T. (2016). Movable anchorage systems for vibration control of stay-cables in bridges. Engineering Structures, 112: 162-171.

Samaras, E., Shonozuka, M. and Tsurui, A. (1985). ARMA representation of random processes. Journal of Engineering Mechanics. ASCE, 111(3): 449-461.

Welch, P. (1967). The use of fast Fourier transform for the estimation of power spectra: a method based on time averaging over short, modified periodograms, IEEE Trans. Audio and Electroacust., Vol. AU-15: 70-73.

Wianecki, J. (1979). Cables wind excited vibrations of cable-stayed bridges. Proceedings of the 5th International Conference of Wind Engineering, Colorado, 1381- 1393. 